DOI: https://doi.org/10.11144/Javeriana.upsy19.sshe

\title{
Social Support in Higher Education: Evidence of Validity and Reliability in the Peruvian Context ${ }^{*}$
}

\section{Apoyo social en educación superior: evidencias de validez y confiabilidad en el contexto peruano}

Denisse Manrique-Millones ${ }^{a}$

Universidad San Martín de Porres, Perú

ORCID: https://orcid.org/0000-0003-4602-5396

Rosa Millones-Rivalles

Universidad de Lima, Perú

ORCID: https://orcid.org/0000-0002-5798-6216

Sergio Dominguez-Lara

Universidad Privada San Juan Bautista, Perú

ORCID: https://orcid.org/0000-0002-2083-4278

Claudia Pineda-Marín

Fundación Universitaria Konrad Lorenz, Colombia ORCID: https://orcid.org/0000-0002-0952-6522

Oscar Manrigue-Pino

Universidad Católica Sedes Sapientiae, Perú ORCID: https://orcid.org/0000-0001-6256-5590

a Correspondence author. denissemanriquemillones@gmail.com

How to cite: Manrique-Millones, D., MillonesRivalles, R., Dominguez-Lara, S., Pineda-Marín, C., Manrique-Pino, O. (2020). Social support in higher education: Evidence of validity and reliability in the Peruvian context. Universitas Psychologica, 19, 1-11. https://doi.org/10.11144/Javeriana.upsy19.sshe
Received: 28 August 2018 | Accepted: 24 October 2020

\begin{abstract}
Social support is a useful cornerstone concept that describes how positive human relationships and social networks allow people to overcome stressful events they face during their lives and to find themselves in a state of relative well-being. This study aims to assess the psychometric properties of the Social Support Appraisals Scale (SS-A) in a Peruvian sample. Participants were 417 undergraduate's students in Metropolitan Lima $\left(M_{\text {age }}=21.78, S D=4.09\right)$. Cross-sectional data was collected after approval by the ethical committee and authorization of all parties involved. A theoretical three-factor model was tested using confirmatory factor analysis. Results showed good fit indexes and revealed that the SS-A's three-dimensional structure was invariant across gender and presented adequate reliability. Likewise, social support showed significant correlations to academic stress. Although the results' generalizability due to the non-random nature of the data presents a caveat, the current findings reveal preliminary evidence that the adapted version of the Social Support Appraisals Scale is a reliable and valid instrument for the assessment of perceived social support in this sample of Peruvian college students.

Keywords

Social Support; validation; reliability; Peru; university students.
\end{abstract}

\section{RESUMEN}

El apoyo social es un concepto fundamental que describe cómo las relaciones humanas positivas y las redes sociales permiten a las personas superar eventos estresantes y encontrarse en un estado de relativo bienestar. Este estudio tiene como objetivo evaluar las propiedades psicométricas de Social Support Appraisals Scale (SS-A) en una muestra peruana. Los participantes fueron 417 estudiantes universitarios de 
Lima Metropolitana. $\left(M_{\text {edad }}=21.78, D E=4.09\right)$. La recolección de los datos se llevaron a cabo después de la aprobación del comité de ética y autorización de todas las partes involucradas Se evaluó un modelo teórico de tres factores utilizando análisis factorial confirmatorio. Los resultados mostraron buenos índices de ajuste y revelaron que la estructura tridimensional del SS-A era invariable en función del género y presentaba una fiabilidad adecuada. Asimismo, el apoyo social mostró correlaciones significativas con el estrés académico. A pesar de que una de las limitaciones está relacionada a la naturaleza no aleatoria de los datos, los hallazgos revelan evidencia preliminar que el Social Support Appraisals Scale es un instrumento confiable y con evidencias de validez para la evaluación del apoyo social percibido en esta muestra de estudiantes universitarios peruanos.

Palabras clave

Apoyo social; validación; confiabilidad; Perú; estudiantes universitarios.

Social support is a continually studied construct, mainly for its implications on people's health and emotional well-being (Novoa \& Barra, 2015). Although the concept of social support lacked boundaries leading in the $80 \mathrm{~s}$, to some extent, there currently is some consensus regarding its definition (Alonso-Fachado, 2008). The conceptual complexity of social support is a consequence of its multidimensionality. Social support is, in the words of Vaux, a "metaconstruct" (Vaux et al., 1986, p. 196) that encompasses different elements such as network resources, supportive acts, and subjective appraisals. This last aspect is particularly relevant to defining social support as a concept. Several theorists (Vaux et al., 1986) have shed some light on the significant role of the "belief that he is cared for and loved, esteemed, and a member of a network" (Cobb, 1976, p. 300) as a definition of social support. This subjective perception point of view of support has been linked with physical well-being (Koetsenruijter et al., 2015) as well as emotional health-related variables such as anxiety (Jacobson et al., 2017; Razurel et al., 2017), depression (Anderson et al., 2017; Frison $\&$ Eggermont, 2015) and mood disorders (LynchJordan et al., 2015; Studart et al., 2015) among others.
In the educational field, social support is known to provide students with the means to combat academic stress (Fernández-Lasarte et al., 2019; Li et al., 2018). The more support a student receives, the less the psychological and physical reactions to their stressors (Yildirim et al., 2017). In fact, social support has been found to have both direct and buffering effects on academic stress symptoms (Lee \& Goldstein, 2016).

Academic stress is a form of stress commonly experienced in the educational field and can negatively impact the student's performance. Research studies on the subject have shown highstress indexes within the university environment, reaching a higher incidence during the periods immediately before exams (Stojanovic et al., 2018). The student perception of social support is a coping strategy that enhances academic achievement preventing school disengagement (Gutiérrez et al., 2017).

The conceptual heterogeneity of social support has also led to the construction of several instruments intended to measure it, but without a clear definition of which dimension of its construct was being measured (Terol et al., 2004). Each one of them has been constructed for populations with specific characteristics: Family APGAR (Smilkstein, 1978), as its name indicates the only source of social support would come from family; Duke-UNC Functional Social Support Questionnaire (Broadhead et al., 1988), measures confidential and affective social support and does not consider the social network; and the MOS-SSS questionnaire (Sherbourne $\&$ Stewart, 1991) designed for people with chronic diseases; are some examples. Despite the significant contribution made by each of these instruments, they assess social support exclusively from a perceived point of view.

The Social Support Appraisals Scale (SS-A; Vaux et al., 1986) has been translated into different languages: German (Laireiter, 2005), Turkish (Gökler, 2007), Chinese (Xin et al., 2007), Persian-Farsi (Abdollahzade Rafi et al., 2012), Portuguese (Antunes \& Fontaine, 2005) and others. It is a psychometrically sound tool that, together with its easy administration, makes 
its use widely spread among social researchers. It has thus been deemed adequate across diverse cultures, consistently demonstrating good reliability and validity properties.

In Spanish-speaking countries, two instrumental studies analyzing the structure of SS-A were found. Cárdenas-Castro et al. (2015) adapted and validated a reduced version of 10 items distributed in two out of the three dimensions (perceived social support of friends and family) in a Chilean university student sample. The results confirmed the SS-A as a useful tool in the Chilean context. Likewise, Nava et al. (2015) adapted the instrument to the Mexican sample. Vaux et al. (1986) proposed a theoretical structure corroborated by using exploratory factor analysis, evidencing that SS$\mathrm{A}$ is an appropriate instrument to be used in Mexico.

Although the Spanish versions of the SS-A provide an important methodological contribution in each of their contexts, one drawback is the lack of contrast with related variables, which increased the test's robustness. Likewise, another void in these investigations is the lack of measurement invariance tested across groups, which would have allowed asserting the meaning of the scale items across participants (Manrique-Millones et al., 2014; Milfont \& Fischer, 2010).

Measurement invariance is a method that allows verifying the coherence of the underlying construct across groups. It is necessary to ensure that the perceived social support has the same meaning for men and women and that its dimensions are also similarly perceived across gender while using the SS-A. Therefore, measurement invariance is a requirement for the subscales' validity across specific groups (Pendergast et al., 2017).

In Peru, Caycho et al. (2014) validated the Duke-UNC Functional Social Support Questionnaire in a specific sample of Peruvian migrants living in Italy. For the rest, different social support measures have been applied using validations from neighboring countries such as Argentina (Rodríguez \& Enrique, 2007). One misconception is to assume that if an instrument has had good psychometric results in one cultural group, it will behave the same. However, this is not always the case (Milfont \& Fischer, 2010).

The present study aims to examine some psychometric properties of the adapted version of the SS-A within a Peruvian university student sample. This was tackled using Confirmatory Factor Analysis (CFA), testing the three-factor model proposed by Vaux et al. (1986) in the original instrument and replicated in the study by Nava et al. (2015) for the Mexican context. Furthermore, a multi-group CFA across gender was conducted to test if the factor structure is consistent between females and males, and reliability was analyzed. Finally, associations between the SS-A and SISCO Inventory of Academic Stress (Barraza, 2006) were explored. We hypothesized a positive relationship between coping and the three subscales of Perceived Social Support: Family, friends, and others (Amaya-Ropero \& CarrilloGonzález, 2015; García et al., 2016), as well as a negative relationship between symptoms, stressors subscales of academic stress and perceived social support subscales (Howard et al., 2017; Nabi et al., 2013).

\section{Method}

\section{Participants}

The study included 427 undergraduate students from two private universities in Metropolitan Lima. Prior to data analysis, we examined possible outliers: 10 participants were excluded because their ages (from 45 to 53 years old) were outside the intended range. The final sample included 417 students. Ages ranged from 17 to 31 years $\left(\mathrm{M}_{\text {age }}=21.78, \mathrm{SD}=4.09, \mathrm{Mdn}=20\right)$. From the total sample, 110 (26.4\%) participants were male, and 307 (73.6 \%) were female. Likewise, $167(40.1 \%)$ students mentioned that they work at least two hours per week, and 250 (59.9\%) were devoted exclusively to study. 


\section{Materials}

Social Support Appraisals Scale (SS-A; Vaux et al., 1986). The SS-A is a self-report questionnaire that highlights the degree to which a person feels loved and part of a group such as family or friends. In its adapted version for the Mexican culture (Nava et al., 2015) encompassed 15 items distributed in three factors as the original instrument: Family (6 items), includes statements such as "My family cares for me very much"; Friends (6 items) "My friends respect me" and Others (3 items) "I am respected by other people". Subjects respond to statements on a four-point Likert scale ranging from "totally agree" to "totally disagree." The Family and Friends scores oscillated between 6 to 24 points, and Others scores ranged from 6 to 12 points.

Previous studies (Nava et al., 2015) have proven good reliability on all three scales, Family $(\alpha=0.82)$, Friends $(\alpha=0.87)$ and Others $(\alpha$ $=0.64)$, as well as the theoretical structure proposed by Vaux et al. (1986) was corroborated using exploratory factor analysis.

The SISCO Inventory of Academic Stress (SISCO; Barraza, 2006). The SISCO Inventory assesses the degree of academic stress in students of upper education or postgraduates. It is composed of 31 items assigned to 3 subscales or factors: Stressors identify the frequency in which the environmental demands are valued as stressors, containing 9 items; Symptoms identify the frequency in which the symptoms are presented, consisting of 18 items; and Coping identifies the frequency of coping strategies through 8 items.

Students rate the frequency of each behavioral item on a 5-point Likert scale ranging from 'never' to 'always'. The validated Peruvian version was used, showing good internal consistency $(\rho=0.69$ to 0.88$)$ and validity (CFI $=0.95$; $\mathrm{RMSEA}=0.050$, CI $90 \%=0.046$, 0.054). (Manrique-Millones et al., 2019).
Procedures

The present research was a cross-sectional study. Non-random data was collected in two private universities in Metropolitan Lima. An institutional review board in Perú (i.e., The Research Committee of the Universidad San Martín de Porres in Perú) provided ethical clearance for conducting the research. Likewise, authorization of the directory was obtained. The original author of the instrument was contacted, and the use of the scale was approved. Questionnaires were administered to the students in their respective classes, collectively, informing them about the study's purpose and the conditions of anonymity.

Undergraduates were informed of the voluntary nature of participation and the confidentiality of the information given. Likewise, they gave informed consent before proceeding. This activity took place during regular university hours, consisting of one session which lasted around 40 minutes. Participation was nearly unanimous, with only one student refusing to participate due to health issues.

\section{Statistical Analysis}

Descriptive analysis was conducted using SPSS v20. Missing data was at random and encompassing $1 \%$ of the total sample, which was handled by replacing median distribution. Factor scores were calculated by adding the scores of the items on each subscale.

The validity of the three-factor model was assessed with Confirmatory Factor Analysis, using LISREL 9.20. The chosen estimation method was Diagonally Weighted Least Squares DWLS (with asymptotic covariance and polychorical correlation matrices) because of the items' ordinal scale nature and related issues of multivariate non-normality (Jöreskog \& Sörbom, 2015).

We used the Comparative Fix Index (CFI) and the Root Mean Square Error of Approximation (RMSEA) to evaluate model fit. Model fit is considered acceptable if CFI is close to 0.90, 
but above 0.95 indicates a good fit. Concerning RMSEA, a value of 0.08 shows an acceptable fit and close to or below 0.06 indicates a good fit (Chen, 2007; Kline, 2011). Factor loadings above 0.50 were considered significant (DominguezLara, 2018).

Measurement Invariance Analysis was performed to investigate whether the internal structure differs for female or male students. A stepwise Multi-Group Confirmatory Factor Analysis (MGCFA) was used to evaluate nested models with gradually increasing parameters constrained (Pendergast et al., 2017). The invariance of the measurement model was tested in terms of factorial structure (configural invariance). If the model is satisfied, it means that participants from different groups have the same conception of the construct under evaluation. We test this first or baseline model by constraining the factorial structure to be invariant across groups. In the following step, we evaluate item loadings in factors (metric invariance); in this case, the aim is to know whether participants in different groups respond to items in the same way. If the model is satisfied, ratings are comparable across groups. This model is assessed by constraining the factor loadings to be invariant across groups. Further, scalar invariance was evaluated in which the intercepts are set equal across groups. Finally invariance of measurement errors was tested, in which all error variances are constrained to be equal across groups.

Regarding metric invariance, a model fit should not be significantly worse than the configural level. Specific criteria need to be applied to assess the differences in fit criteria between successive levels of measurement invariance. Such differences should not exceed 0.010 for the CFI $(\Delta$ CFI $<0.010$; Cheung \& Rensvold, 2002), and 0.015 for the RMSEA (Chen, 2007).

Furthermore, associations between Social Support Appraisals Scale and SISCO Academic Stress Inventory were inspected by means of Pearson's correlation. Reliability was evaluated with Jöreskog's Rho ( $\rho)$ (Schweizer, 2011).

\section{Results}

Confirmatory Factor Analysis. CFA was performed to analyze whether the scales' factorial structure could be retrieved in a Peruvian sample. The three-factor model showed a good fit of the data, with SB- $\chi^{2}(87)=184.22$, CFI $=0.99$, RMSEA $=0.05,90 \%$ CI $[0.04,0.06]$.

The standardized factor loadings were, except only one item, above the conventional threshold, according to which a standardized loading greater than 0.50 is considered very significant (see Table 1).

Regarding factor correlations, intercorrelations were significant and high between the factors family and friends $(r=0.61 ; t=5.57$; $p<0.001)$ and family and others $(r=0.75 ; t=$ 7.55; $p<0.001)$; and moderate between others and friends $\left({ }^{\prime} r=0.48 ; t=5.20 ; p<0.001\right)$.

\section{Table 1}

SS-A Primary Factor Loadings, Internal Consistency, Means and Standard Deviations for Three-factor model

\begin{tabular}{lrrr}
\hline \multirow{2}{*}{ Item } & \multicolumn{3}{c}{ Three- Factor Model } \\
\cline { 2 - 4 } & Family & Friends & Others \\
\hline FAM1 & 0.71 & & \\
FAM2 & 0.83 & & \\
FAM3 & 0.88 & & \\
FAM4 & 0.79 & & \\
FAM5 & 0.93 & & \\
FAM6 & -0.47 & & \\
FRI1 & & 0.64 & \\
FRI2 & & 0.71 & \\
FRI3 & & 0.82 & \\
FRI4 & & 0.87 & \\
FRI5 & & 0.69 & \\
FRI6 & & 0.71 & \\
OTH1 & & & 0.67 \\
OTH2 & & & 0.57 \\
OTH3 & & & 0.80 \\
\hline Coefficients & & & \\
Jöreskog Rho & 0.85 & 0.88 & 0.72 \\
Mean & 19.49 & 18.8 & 9.47 \\
SD & 2.3 & 2.94 & 1.27 \\
\hline
\end{tabular}


MultiGroup Confirmatory Factor Analysis. To test whether the factor structure is comparable for female and male students, an MGCFA was conducted for the three-factor model.

The fit of the configural model was acceptable $\mathrm{SB}-\chi^{2}(174)=272.82, \mathrm{CFI}=0.98, \mathrm{RMSEA}=$ 0.05 . In Step 2 , the factor loadings $(\Lambda)$ were constrained to be equal groups. This level of invariance was nested within the previous model (configural). The fit of this model was also acceptable SB- $\chi^{2}(189)=291.72, \mathrm{CFI}=0.98$, RMSEA $=0.05$. There is a tendency to look at the difference between CFI values, suggesting that difference values should not exceed .01 . Relying on this criterion, factor loadings between girls' and boys' sample were considered invariant. Further, in step 3, the fit of the scalar model (intercepts constrained to be equal across groups) was again acceptable SB- $\chi^{2}(192)=294.23$, $\mathrm{CFI}=0.98$, RMSEA $=0.05$. Finally, in step 4 error invariance was constrained to be equal across groups with an acceptable fit SB- $\chi^{2}$ (207) $=305.61, \mathrm{CFI}=0.98$, RMSEA $=0.05$. The Social Support Appraisals Scale therefore shows factorial invariance across females and males, which can be seen in table 2 .

\section{Table 2}

Measurement invariance across gender

\begin{tabular}{lrrrr}
\hline \multicolumn{1}{c}{ Model } & RMSEA (90\%CI) & SRMSEA & CFI & \multicolumn{1}{c}{ ACFI } \\
\hline Configural Model & $0.05(0.04-0.06)$ & & 0.982 & \\
$\Lambda$ invariant & $0.05(0.04-0.06)$ & 0.001 & 0.981 & 0.001 \\
$\Lambda \Phi$ invariant & $0.05(0.04-0.06)$ & 0.001 & 0.981 & 0 \\
$\Lambda \Phi \Theta_{\delta}$ invariant & $0.05(0.04-0.06)$ & 0.002 & 0.982 & 0.001 \\
\hline
\end{tabular}

Note. $\Delta=$ LMetric Invariance Model; $\Delta \Phi=$ Scalar Invariance Model; $\Delta \Phi \Theta_{\delta}=$ Invariance of Measurement Errors Model; RMSEA = Root Mean Square Error of Approximation; $\triangle$ RMSEA = difference in Root Mean Square

Error of Approximation between nested models; CFI = Comparative Fit Index; $\Delta$ CFI

$=$ Difference in index between nested models.

Reliability.Table 1 shows Jöreskog's Rho's (p). All sub-scales present acceptable internal consistency above .50 , ranging from .72 (others) to 0.85 (friends). Nevertheless, if removing item FAM6 from family sub-scale, reliability improves $(p=0.92)$.

Social Support- Academic Stress. The scale Coping was significantly associated with Family $(r=0.21)$, friends $(r=0.22)$ and others $(r=0.23)$. Furthermore, Symptoms showed a negative correlation with the three social support subscales. Likewise, the Stressors scale was negatively associated to Friends $(r=-0.15)$ and Others $(r=-0.14)$. Finally, the Stressors scale did not show significant associations to the Family subscale.

\section{Discussion}

Social Support Appraisals Scale is an instrument that provides valuable information about each person's help he or she believes in receiving. Its efficiency has been proven in diverse cultures: Mexican (Nava et al., 2015) and Brazilian (Leme, 2013). These examples of Latin-American context showed evidence of the multidimensionality of its structure.

Our goal was to test some psychometric properties in a Peruvian sample. To fulfill this aim, we first evaluated the factorial structure of the scale. Secondly, we tested the Measurement Invariance (MI) across gender. After that, we inspected the reliability of the subscales, and finally, we performed associations with one related variable (academic stress).

Concerning the factor structure, we were able to verify the scale's dimensionality, which is shown as an appropriate instrument, and the three-factor model based on literature (Vaux et al., 1986) could be confirmed in the Peruvian sample and replicated in diverse cultures. Multigroup Confirmatory Factor Analysis confirmed the latent structure's invariance across gender and the robustness of the 3-factor structure. Measurement invariances (MI) evaluated in this study involved examining a set of increasingly restrictive models: the configural invariance model, the metric invariance model, the scalar invariance model and the error variance invariance model. As pointed out before, MI has not been addressed in previous attempts to measure social support appraisals (SS-A), and it is important as it proves that the SS-A scores are unaffected by gender bias. 
Some studies claim to have found gender differences (Soman et al., 2016), yet without analyzing gender measurement invariance, one cannot be certain of such results' the validity.

All three sub-scales Family, Friends, and Others had reliability above the specialized psychometric literature's cutoff. These results are similar to what is reported in several studies with the SS-A (Cárdenas-Castro et al., 2015; Squassoni \& Matsukura, 2014).

The instrument also showed significant positive correlations with the subscale Coping of the Academic Stress Scale (Wenli et al., 2016), hence the higher the perceived social support of a student, the greater coping strategies he/ she might use (Perera \& Digiacomo, 2015). A negative association with the subscale Symptoms and Stressors was found, meaning that perceived social support and academic stress of college students are inversely proportional (Glozah \& Pevalin, 2014).

Results confirmed the hypothesized relationships between perceived social support and academic stress (Khan et al., 2016). Academic stress can lead to a deficient performance in the university, in which students frequently experience a lack of concentration, having an impact on their productivity (Essel \& Owusu, 2017). Nonetheless, the social support's protective role can encourage student motivation and commitment to learning activities (Dupont et al., 2015).

Perceived family support has been shown to improve student interest and academic achievement (Mattanah et al., 2011). Likewise, when students perceive the support of friends, they are stimulated, not only at the cognitive but also at the emotional aspect (Friedlander et al., 2007). One can conclude that perceived social support is crucial for preventing or reducing academic shortcomings.

Notwithstanding, some limitations have to be addressed. First, in this study, we used a non-random sample; consequently, this group only represents a population sector, with specific characteristics: university students from private institutions. Therefore, it is recommendable for future studies, expanding the research, and carrying out studies with different samples, involving public institutions and other Peru regions to have a more representative sample at a macro level. Second, related to the nature of the data (cross-sectional). Collecting information at a single point in time can be disadvantageous due to susceptibility to errors (biases and confounding factors). For future research, we suggest longitudinal studies that can establish causal relationships between variables and thus provide more reliable inferences. Finally, although we have used an alternative measure of reliability $(\rho)$ that seems adequate to the data features than Cronbach's alpha (Sijtsma, 2009), test-retest reliability could have given more stability across time.

\section{Conclusions}

To summarize, the present study results provide empirical support for the factorial structure of the Social Support Appraisals Scale. In this sense, the SS-A can be seen as a trustworthy measure for assessing social support in this particular sample and can be used for meaningful comparisons across gender. It can also be considered to assess the relationship between stressful events in the school setting and social support in education at home, guided by technology and social isolation. Results bode well for this tool's utility and its applicability to diverse groups, contexts, and regions in Latin America.

\section{References}

Abdollahzade Rafi, M., Hassanzadeh, M., Ahmadi, S., Taheri, M., \& Hosseini, M. A. (2012). Relationship between social support with depression and anxiety during third trimester pregnancy. Iranian Journal of Nursing Research, 7(26), 1-10. http://ijnr.ir/ article-1-1051-en.html

Alonso-Fachado, A. (2008). Influencia del Apoyo Social en el control metabólico de la diabetes mellitus tipo 2. [Doctoral Dissertation, Universidad de Santiago de Compostela, La Coruña, Spain]. Minerva Repositorio 
Institucional Da ISC. http://hdl.handle.net /10347/2581

Amaya-Ropero, M. C., \& Carrillo-González, G. M. (2015). Apoyo social percibido y afrontamiento en personas con dolor crónico no maligno [Perceived social support and coping in people with chronic non-malignant pain]. Aquichan, 15(4), 461-474. https://doi.org/10.5294/aqui.2015 .15 .4 .2

Anderson, D. R., Roubinov, D. S., Turner, A. P., Williams, R. M., Norvell, D. C., \& Czerniecki, J. M. (2017). Perceived social support moderates the relationship between activities of daily living and depression after lower limb loss. Rehabilitation Psychology, 62 (2), 214-220. ht tps://doi.org/10.1037/rep0000133

Antunes, C., \& Fontaine, A. M. (2005). Percepção de apoio social na adolescência: Análise fatorial confirmatória da escala Social Support Appraisals [Perception of social support in adolescence: Confirmatory factor analysis of the Perceived Social Support Appraisals Scale]. Paidéia (Ribeirão Preto), 15(32), 355-366. https://doi.org/10. 1590/S0103-863X2005000300005

Barraza, A. (2007). Propiedades psicométricas del Inventario SISCO del Estrés Académico. [Psychometric properties of SISCO Inventory of Academic Stress]. Revista PsicológicaCientífica.com, 9(10). https://www.psicologiacientifica.co $\mathrm{m} /$ sisco-propiedades-psicometricas/

Broadhead, W. E., Gehlbach, S. H., DeGruy, F. V., \& Kaplan, B. H. (1988). The Duke-UNC Functional Social Support Questionnaire: Measurement of social support in family medicine patients. Medical Care, 26(7), 709-723.https://doi.org/10.109 7/00005650-198807000-00006

Cárdenas-Castro, M., Barrientos Delgado, J., \& Ricci Alvarado, E. (2015). Estructura factorial de la escala de soporte social subjetivo: validación en una muestra de estudiantes universitarios chilenos [Factor structure of the Subjective Social Support Scale: validation with a sample of university students in Chile]. Acta Colombiana de Psicología, 18(1), 95-101. https://doi.org/10 .14718/acp.2015.18.1.9

Caycho, T., Dominguez, S., Villegas, G., Sotelo, N., \& Carbajal, C. (2014). Análisis psicométrico del Cuestionario de Apoyo Social Funcional DUKEUNK-11 en inmigrantes peruanos en Italia [Psychometric analysis of Functional Social Support Questionnaire DUKEUNK-11 in Peruvian migrants in Italy]. Pensamiento Psicológico, 12(2), 25-35. https://revistas.javerianacali.edu.co/ index.php/pensamientopsicologico/article/ view/737

Chen, F. F. (2007). Sensitivity of goodness of fit indexes to lack of measurement invariance. Structural Equation Modeling: A Multidisciplinary Journal, 14(3), 464-504. ht tps://doi.org/10.1080/10705510701301834

Cheung, G. W., \& Rensvold, R. B. (2002). Evaluating goodness-of-fit indexes for testing measurement invariance. Structural Equation Modeling, 9(2), 233-55. https://doi .org/10.1207/s15328007sem0902_5

Cobb, S. (1976). Social support as a moderator of life stress. Psychosomatic Medicine, 38(5), 300-314. https://doi.org/10.1097/00006842 $-197609000-00003$

Dominguez-Lara, S. (2018). Proposal for cutoffs for factor loadings: A construct reliability perspective. Enfermería Clínica, 28(6), 401-402. https://doi.org/10.1016/j.e nfcle.2018.06.006

Dupont, S., Galand, B., \& Nils, F. (2015). The impact of different sources of social support on academic performance: Intervening factors and mediated pathways in the case of master's thesis. Revue Européenne de Psychologie Appliquée, 65(5), 227-237. https ://doi.org/10.1016/j.erap.2015.08.003

Essel, J., \& Owusu, P. (2017). Causes of students' stress, its effects on their academic success, and stress management by students. (Master Thesis, Seinäjoki University of Applied Sciences, Finland). Theseus. http://urn.fi/U RN:NBN:fi:amk-201704134793 
Fernández-Lasarte, O., Ramos- Diaz, E., \& Axpe Saez, I. (2019). Rendimiento académico, apoyo social percibido e inteligencia emocional en la universidad [Academic performance, perceived social support, and emotional intelligence in college]. European Journal of Investigation in Health, Psychology and Education, 9(1), 39-49. https://oi.org/ 10.30552/ejihpe.v9i1.315

Friedlander, L. J., Reid, G. J., Shupak, N., \& Cribbie, R. (2007). Social support, self-esteem, and stress as predictors of adjustment to university among first-year undergraduates. Journal of College Student Development, 48(3), 259-274. https://doi.or $\mathrm{g} / 10.1353 / \mathrm{csd} .2007 .0024$

Frison, E., \& Eggermont, S. (2015). Exploring the relationships between different types of Facebook use, perceived online social support, and adolescents' depressed mood. Social Science Computer Review, 34(2), 153-171. https://doi.org/10.1177/08944393 14567449

García, F., Manquián, E., \& Rivas, G. (2016). Evaluating goodness-of-fit indexes for testing measurement invariance Bienestar psicológico, estrategias de afrontamiento y apoyo social en cuidadores informales. Psicoperspectivas, 15(3), 101-111. https://doi.org/10.5027/psi coperspectivas-vol15-issue 3 -fulltext-770

Glozah, F., \& Pevalin, D. (2014). Social support, stress, health, and academic success in Ghanaian adolescents: A path analysis. Journal of Adolescence, 37(4), 451-460. https://doi.org/10.1016/j.adolesce nce.2014.03.010

Gökler, I. (2007). The Turkish adaptation study of social support appraisals scale to be used with children and adolescents: Factor structure, validity and reliability. Turkish Journal of child Adolescent Mental Health, 14, 90-99.

Gutiérrez, M., Tomás, J. M., Romero, I., \& Barrica, J. M. (2017). Perceived social support, school engagement and satisfaction with school. Revistade
Psicodidáctica, 22(2), 111-117. https://doi.o rg/10.1016/j.psicoe.2017.05.001

Howard, S., Creaven, A. M., Hughes, B., O'Leary, E., \& James, J. (2017). Perceived social support predicts lower cardiovascular reactivity to stress in older adults. Biological Psychology, 125, 70-75. https://doi.org/10.1 016/j.biopsycho.2017.02.006

Jacobson, N. C., Lord, K. A., \& Newman, M. G. (2017). Perceived emotional social support in bereaved spouses mediates the relationship between anxiety and depression. Journal of Affective Dissorders, 211, 83-91. https://dx.doi.org/10.1016/j.jad .2017 .01 .011

Jöreskog, K., \& Sörbom, D. (2015). LISREL 9.20 for windows. [Computer software]. Skokie, IL: Scientific.

Khan, A., Hamdan, A., Ahmad, R., Mustaffa, M., \& Mahalle, S. (2016). Problem-solving coping and social support as mediators of academic stress and suicidal ideation among malaysian and indian adolescents. Community Mental Health Journal, 52, 245-250. https://doi.org/10.1007/s10597-0 $15-9937-6$

Kline, R. B. (2011). Principles and practice of structural equation modeling (3rd ed.). New York, NY: Guilford Press.

Koetsenruijter, J., van Lieshout, J., Lionis, C., Portillo, M. C., Vassilev, I., Todorova, E., Foss, C., Serrano-Gil, M., Ruud, I., Angelaki, A., Mujika, A., Roukova, P., Kennedy, A., Rogers, A., \& Wensing, M. (2015). Social Support and Health in Diabetes Patients: An Observational Study in Six European Countries in an Era of Austerity. PLoS ONE, 10(8), e0135079. htt ps://doi.org/10.1371/journal.pone.0135079

Laireiter, A. R. (2005). Skalen Soziale Unterstützung [Scales of social support]. Mödling: Schuhfried.

Lee, C. S., \& Goldstein, S. E. (2016) Loneliness, Stress, and Social Support in Young Adulthood: Does the Source of Support Matter? Journal of Youth and Adolescence 45, 568-580. https://doi.org/10.1007/s1096 4-015-0395-9 
Leme, V. B. R. (2013). Adolescentes de famílias nucleares, monoparentais e recasadas: Relações entre práticas parentais, habilidades sociais, bem-estar psicológico e percepção de apoio social (Protocol No. 11/05321-4). São Paulo, SP: FAPESP. Unpublished Research Report.

Li, J., Han, X., Wang, W., Sun, G., \& Cheng, Z. (2018). How social support influences university students' academic achievement and emotional exhaustion: The mediating role of self-esteem. Learning and Individual Differences, 61, 120-126. https://doi.org/10. 1016/j.lindif.2017.11.016

Lynch-Jordan, A. M., Sil, S., Bromberg, M., Ting, T. V., \& Kashikar-Zuck, S. (2015). CrossSectional study of young adults diagnosed with juvenile fibromyalgia: Social Support and its impact on functioning and mood. Journal of Adolescent Health, 57(5), 482-487. https://doi.org/10.1016/j.jadoheal th.2015.07.015

Manrique-Millones, D. L., Ghesquière, P., \& Van Leeuwen, K. (2014). Evaluation of a parental scale in a Peruvian Context. Journal of Child and Family Studies, 23, 885-894. https://doi.org/10.1007/s10826-0 13-9744-z

Manrique-Millones, D., Millones-Rivalles, R., \& Manrique-Pino, O. (2019). The SISCO Inventory of Academic Stress: Examination of its psychometric properties in a Peruvian sample. Ansiedad y Estrés, 25 (1), 28-34. htt ps://doi.org/10.1016/j.anyes.2019.03.001

Mattanah, J. F., Lopez, F. G., \& Govern, J. M. (2011). The contributions of parental attachment bonds to college student development and adjustment: A metaanalytic review. Journal of Counseling Psychology, 58(4), 565-596. http://dx.doi.or g/10.1037/a0024635

Milfont, T. L., \& Fischer, R. (2010). Testing measurement invariance across groups: Application in cross-cultural research. International Journal of Psychological Research, 3(1), 111-121. https://doi.org/10. 21500/20112084.857
Nava, C. N., Bezies, R., \& Vega, C. Z. (2015). Adaptación y validación de la escala de percepción de apoyo social de Vaux [Adaptation and Validation of the Scale of Perceived Social Support from Vaux]. Liberabit, 21(1), 49-58. http://www.scielo.org.pe/scielo.php? script $=$ sci_arttext\&pid=S1729-48272015 $00010000 \overline{5}$

Nabi, R. L., Prestin, A., \& So, J. (2013). Facebook friends with (health) benefits? exploring social network site use and perceptions of social support, stress, and well-being. Cyberpsychology, Behavior, and Social Networking, 16(10), 721-727. https:// doi.org/10.1089/cyber.2012.0521

Novoa, C., \& Barra, E. (2015). Influencia del apoyo social percibido y los factores de personalidad en la satisfacción vital de estudiantes universitarios. Terapia Psicológica, 33(3), 239-245. https://doi.org/ 10.4067/s0718-48082015000300007

Pendergast, L. L., von der Embse, N., Kilgus, S. P., \& Eklund, K. R. (2017). Measurement equivalence: A non-technical primer on categorical multi-group confirmatory factor analysis in school psychology. Journal of School Psychology, 60, 65-82. https://doi.org /10.1016/j.jsp.2016.11.002

Perera, H., \& Digiacomo, M. (2015). The role of trait emotional intelligence in academic performance during the university transition: An integrative model of mediation via social support, coping, and adjustment. Personality and Individual Differences, 83, 208-213. https://doi.org/10. 1016/j.paid.2015.04.001

Razurel, Ch., Kaiser, B., Antonietti, J-P., Epiney, M., \& Sellenet, C. (2017). Relationship between perceived perinatal stress and depressive symptoms, anxiety, and parental self-efficacy in primiparous mothers and the role of social support. Women and Health, 57(2), 154 -172. https://doi.org/10.1080/03 630242.2016.1157125

Rodríguez, S., \& Enrique, H. (2007). Validación Argentina del Cuestionario MOS de Apoyo 
Social Percibido. Psicodebate, 7, 155-68. htt ps://doi.org/10.18682/pd.v7i0.433

Schweizer, K. (2011). On the changing role of Cronbach's alpha in the evaluation of the quality of a measure. European Journal of Psychological Assessment, 27, 143-144. https ://doi.org/10.1027/1015-5759/a000069

Sherbourne, C. D., \& Stewart, A. L. (1991). The MOS Social Support Survey. Social Science Eु Medicine, 32 (6), 705-714. https://doi.org /10.1016/0277-9536(91)90150-b

Sijtsma, K. (2009). On the use, the misuse, and the very limited usefulness of Cronbach's Alpha. Psychometrika,74, 107-120. https://d oi.org/10.1007/s11336-008-9101-0

Smilkstein, G. (1978). The family APGAR: A proposal for a family function test and its uses by physicians. The Journal of Family Practice, 6(6), 12311239. https://mdedge-files-live.s3.us-east-2 .amazonaws.com/files/s3fs-public/jfp-archi ved-issues/1978-volume 6-7/JFP 1978-06 v6 i6 the-family-apgar-a-proposal-for-a-f amily.pdf

Soman, S., Bhat, S. M., Latha, K. S., \& Praharaj, S. K. (2016). Gender differences in perceived social support and stressful life events in depressed patients. East Asian Archives of Psychiatry, 26(1), 22-29.

Squassoni, C. E., \& Matsukura, T. S. (2014). Adaptação transcultural da versão portuguesa do social support appraisals para o Brasil [Cross-Cultural Adaptation of the Portuguese Version of Social Support Appraisals for Brazil]. Psicologia: Reflexão e Crítica, 27(1), 71-80. https://doi.org/10.159 0/s0102-79722014000100009

Stojanovic, G., Vasiljevic-Blagojevic, M., Stankovic, B., Terzic, N., Terzic-Markovic, D., \& Stojanovic, D. (2018). Test anxiety in pre-exam period and success of nursing students. Serbian Journal of Experimental and Clinical Research, 19(2), 167-174. https://d oi.org/10.1515/SJECR-2017-0060

Studart, P. M., Bezerra, S. B., Studart, A. B. D., Galvão-de Almeida, A., \& Miranda-Scippa, A. (2015). Social support and bipolar disorder. Archives of Clinical
Psychiatry, 42 (4), 95-99. https://doi.org/10. 1590/0101-60830000000057

Terol, M. C., Lopez, S., Neipp, M. C., Rodríguez, J., Pastor, M. A., \& Martin-Aragon, M. (2004). Apoyo social e instrumentos de evaluación: Revisión y clasificación [Social Support and instruments of assessments: Review and classification]. Anuario de Psicología, 35(1), 23-45. https://dialnet.unir ioja.es/servlet/articulo?codigo $=864595$

Vaux, A., Phillips, J., Holly, L., Thomson, B., Williams, D., \& Stewart, D. (1986) The Social Support Appraisals (SS-A) Scale: Studies of reliability and validity. American Journal of Community Psychology, 14(2), 195-219. https://doi.org/10.1007/bf009118 21

Wenli, L., Zhihua, L., Yu, L., \& Taisheng, C. (2016). Core self-evaluations and coping styles as mediators between social support and well-being. Personality and Individual Differences, 88, 35-39. https://doi.org/10.10 16/j.paid.2015.08.044

Xin, Z., Chi, L., Geng, L., Zhao, X., \& Wang, J. (2007). Revision and application of the Social Support Appraisal Scale. Chinese Mental Health Journal, 6, 379-381.

Yildirim, N., Karaca, A., Cangur, S., Acikgoz, F., \& Akkus, D. (2017). The relationship between educational stress, stress coping, self-esteem, social support, and health status among nursing students in Turkey: A structural equation modeling approach. Nurse Education Today, 48, 33-39. https://d oi.org/10.1016/j.nedt.2016.09.014

\section{Notes}

* Research article. 